\title{
MUNDO DA VIDA: PROBLEMA EPISTEMOLÓGICO OU QUESTÃO HISTÓRICA
}

Ernildo Stein*

STINTESE - As limitações filosóficas do conceito de mundo da vida mostram-se numa análise que considera sua dupla função: ser um conceito histórico e ao mesmo tempo um conceito epistemológico. Isso termina revelando a dificuldade na pretensão de unidade do conceito de mundo da vida.
ABSTRACT - The philosophical limitations of the "word of life" (Lebenswelt) concept appear in the analysis which considers its double function, namely as a historical and epistemological moment. This reveals the difficulty to claim unity for the concept here examined.

\section{I - Introdução}

1. Nos momentos mais significativos da filosofia continental, aparece, nos anos 20 e 30, uma questão que revela duas vertentes :

a) como reaproximar, em meio à dominação do neokantismo, das posições psicologistas e do positivismo, a filosofia, da vida; b) isto que parece ser apenas uma volta para um novo objeto da Filosofia, constitui-se, no entanto, também, numa investigação de um novo ponto de partida da Filosofia, levanta uma questão de método.

Nesta preocupação aparece, portanto, uma questão de conteúdo e uma questão de método. E o problema todo que assim se articula, na Filosofia européia, não deixa de ser menos importante e, de certo modo, decisivo, simplesmente porque, no começo, é posto de maneira pouco clara.

Para sua explicitação contribui, justamente, a ampliação de sua aplicação; esta consiste numa espécie de convergência entre Filosofia e Ciências Humanas. É claro que a questão é posta, de maneira mais ampla, sobretudo por Husserl. Importa-nos antes de mais nada, ressaltar aqui o primeiro aspecto referido. Aparentemente se tratava de uma renovação da Filosofia que se impunha ante as novas

- Instituto de Filosofia e Ciências Humanas da PUCRS.

\begin{tabular}{|l|l|l|l|l|l|}
\hline VERITAS & Porto Alegre & v. 42 & $\mathrm{n}^{\mathrm{9}} 1$ & Março 1997 & p. 5-11 \\
\hline
\end{tabular}


formas de vida e os desafios para o pensamento, provindos de uma época conturbada e contraditória. No fundo, porém, estava, sobretudo, em questão a legitimação das ciências humanas e certas discussões de método.

Pouco acrescentaria se fôssemos falar de uma crise da Metafísica, de uma crise de fundamento. Era, sem dúvida, verdadeiro que se vivia a consciência do fim dos grandes sistemas filosóficos, e justamente com o impacto político e social do movimento marxista, impunham-se problemas teóricos novos, com uma "filosofia" chegando ao poder. Seria isto - este fazer-se mundo da Filosofia - que aproximaria a Filosofia da vida concreta?

Mas o surgimento de uma nova questão de objeto e de método na Filosofia, se apresentava muito mais complexo que uma crise da cultura, de transformações sociais e políticas, no fim da era da Metafísica.

2. É por isso que nossa investigação quer mostrar até que ponto a Filosofia passava a enfrentar-se com um novo objeto e até que ponto se desenvolvia um novo método.

A questão de método vinha articulada com a questão de objeto. Isto porque a Filosofia que se compreende como tal, não separa método e objeto. Mas apresenta-se mais, nesta questão. Porque se ela visava justificar sua existência, tomando novo objeto - a vida, o mundo, o mundo da vida, - o que efetivamente acontecia era a busca de uma nova justificação, na Filosofia, uma nova forma de fundamentar, o que significa uma nova face do problema do método.

Tratava-se, certamente, de um novo tema que passa a ocupar, progressivamente, o espaço deixado pelo empenho em sistematizar a partir de um princípio totalizador, ainda metafísico. Mas este novo tema é determinado a partir do fenômeno novo na paisagem cultural, no começo do século: o surgimento das Ciências Humanas.

A perda de grande parte de suas áreas tradicionais para as ciências e, neste ponto, sobretudo, já para as Ciências Humanas que trabalhavam pela sua autonomia e o simultâneo desenvolvimento da Lógica, longe das questões metafísicas, reduziam o campo da Filosofia e lhe davam, sobretudo, uma nova consciência metodológica, um novo estilo de fundamentação, de demonstração, de argumentação, de racionalidade.

O que aqui importa acentuar é que, ainda que progressivamente autônomas, as Ciências Humanas mantiveram uma relação particular de convergência com a Filosofia. Daí, que a questão da vida, do mundo, do ser-no-mundo, do mundo da vida, passou a ser um domínio privilegiado da convergência, por causa do problema da fundamentação das Ciências Humanas. Tudo isso se reforçava a partir de um confronto entre as Ciências Empírico-matemáticas e as Ciências Humanas, na busca de um método que desse autonomia a estas últimas: era o conflito entre o explicar e o compreender. Como legitimariam as ciências emergentes seus enunciados? Como abandonar sua base metafísica a caminho de uma justificação? Era aí que se apresentava o mundo da vida como o fundo intransponivel, para onde remetia toda justificação. 
3. Parece-me forma adequada explorar o conceito de mundo da vida sobre este bastidor ou este pano de fundo, onde se apresentam questões, ao mesmo tempo, históricas e sistemáticas.

Mas é preciso introduzir uma questão mais ampla. A questão do mundo da vida recebe sua legitimação a partir de um novo processo de filosofar, a partir de uma matriz que se caracteriza por apresentar um certo universo de questões, de respostas, de métodos, de justificação, de argumentação, de racionalidade. Falo aqui de um novo paradigma que se configura nos anos 20 e 30, sobretudo na Alemanha, e se dissemina pela França e outros centros universitários de investigação na Europa.

No conceito de mundo da vida inaugura-se, portanto, a retomada de um universo de interrogação que continua a velha temática da fundação da tradição, reposta, no entanto, em nova clave. Não é simplesmente a busca do antepredicativo, daquilo que é anterior a toda experiência, o "logicamente nu" de Wilhelm Szilasi. O mundo vivido é constituído a partir do universo da significação, mas já sempre dado para toda a atividade significativa do ser humano. É, de certo modo, a fonte da significatividade possível, já sempre dada e que, contudo, se atualiza sempre de novo na significação que constitui.

Este novo paradigma toma sua forma, talvez numa tácita luta contra o ceticismo: ou nunca estávamos efetivamente conectados com o mundo ou então corremos o risco de perdê-lo. Não há por que fazer a ponte com o mundo, quando o mundo nos apanha vinculando a linguagem com relações fáticas. São as "formas de vida", expressão da qual ouviremos falar nos anos cinqüenta, quando são publicadas as Investigações filosóficas de Wittgenstein.

Neste paradigma do mundo da vida, uma série de autores convergem para expressar, de diversos modos, a mesma preocupação, ainda que vindos de direções diversas. Mas, não resta dúvida, de que foi no terreno da fenomenologia que o problema recebeu seu tratamento mais adequado. E se hoje um Habermas ou um Giannotti falam da questão, remeterão quase sempre para $A$ crise das ciências européias... de Edmund Husserl.

4. Evidentemente, não passa desapercebido ao estudioso, que este conceito de mundo da vida, além de um problema metodológico e, de certo modo, um problema de objeto, aparece num horizonte em que se revelam certas preocupações com a prática. No modo de ser do ser-aí, por exemplo, em Heidegger, há para ser tematizado e explicitado o problema da cotidianidade. Ser-no-mundo é sempre, antes de tudo, ser-cotidiano. Na analítica do cotidiano se pretende colocar o lugar de onde parte toda investigação e para onde retorna. Mas o que talvez poderia ser compreendido apenas como um princípio epistemológico se revela também como uma espécie de tarefa. Há que redimir o cotidiano, a existência singular; mas esta redenção é, ao mesmo tempo, impossível em plenitude. O cotidiano se manifesta alienado, reificado e isto é uma condição inelutável; há um movimento pendular entre autenticidade e inautenticidade.

A tentativa de recuperar o mundo do cotidiano é, antes de tudo, a empresa de devolver espessura ao ôntico, ao indivíduo em sua rotina. O mundo da vida se 
impõe aí como tarefa, como projeto. Há aqui ressonância de uma luta que se retoma, a um outro nível, em textos como os de Freud e Lukács. Estes dois autores representam como que a contraface da teoria do cotidiano de Heidegger. Temos lá a busca de uma substância do cotidiano, na crítica da representação e da alienação, que procedem do universo social e econômico, enquanto Heidegger não visa as patologias da existência, mas suas estruturas que são o modo de como aparece o cotidiano e que estão na base dos processos que analisaram Freud e Marx.

É esta questão do cotidiano que aparece como um momento importante da questão do mundo da vida, sem, no entanto, anular nela o problema de sua intenção de lugar da fundamentação da Filosofia e das Ciências Humanas. Resta, sem dúvida, uma ambigüidade que afiora, ainda hoje, nas obras de Habermas, em suas análises da relação entre sistema e mundo da vida, quando fala da "colonização do cotidiano".

Nossa investigação toca, portanto, um tema central em que a exploração de certos veios já representará um ganho para a problemática fundadora na Filosofia e nas Ciências Humanas, em nossos dias.

\section{II - Problematização}

1. A vida em sua condição concreto-histórica e a pretensão de universalidade e necessidade do conhecimento filosófico, em busca da racionalidade, sempre conduziram os sistemas e as propostas de filósofos a conflitos. Trata-se, não apenas de conciliar a racionalidade com a factualidade ao nível de fundamentação, portanto, ao nível de conhecimento, mas de fugir a uma culpa de que a filosofia não é capaz de pensar a vida concreta, em sua singularidade e factualidade.

Esta questão se aguçou ainda mais com o nascimento das Ciências Humanas, históricas e sociais, cujo empenho era salvar o singular, o concreto, sem perder o reconhecimento de sua universalidade que lhes garantiria necessidade e racionalidade em face do universo empírico-matemático.

A busca de solução do conflito conduziu na modernidade e conduz ainda hoje a diversos reducionismos, em que principalmente certos métodos de investigação empírica - evolucionismo, estruturalismo, biologismo, organicismo, lingüisticismo, etc - eram apresentados como universais, de modo preponderante para salvar, na Filosofia, a vida, o concreto, o imediato, o histórico. Mas a Filosofia não tem esta vocação de universalizar um método (contingente e singular) de investigação científica para amolecer sua pretensão de racionalidade que não é a mesma que produz o esforço cognitivo e discursivo da ciência.

Portanto, a Filosofia, enquanto busca justificação e fundamentação para o conhecimento no universo concreto-histórico da vida, não renuncia à sua pretensão de desenvolver as condições de possibilidade, do apriori, dos critérios que garantem a racionalidade das ciências humanas, de um lado, e, de outro, continua com a pretensão de dizer algo da vida, das estruturas da realidade, que não se reduz ao discurso científico. 
2. Junto com o conceito de cotidiano, o conceito de mundo da vida cresceu em importância, sobretudo na teoria social e nas Ciências Sociais.

Razões que podemos aduzir para isto: 1. Reabilitação do concreto em face do desenvolvimento científico e tecnológico, ligado a uma crescente abstração e intransparência. 2. Expressão de valorização temporal e social de uma práxis pouco regulamentada e institucionalizada e favorecida pela redução do tempo de trabalho nos úitimos anos. 3. Dificuldade na qual se encontram as Ciências Sociais em sua pesquisa empírica; pelo fato de pressupostos de validade dos resultados da pesquisa considerados evidentes, serem mais e mais questionados, a saber, o pressuposto de significados comuns e idênticos não problematizados.

A problemática desta conjuntura revela diversos riscos: a) culto da imediatidade; b) realismo ingênuo da vida cotidiana; c) atrás dos conceitos de cotidiano e mundo da vida se esconderia uma animosidade contra a ciência e a técnica.

Para esclarecer esta situação se deveria investigar: 1) A história do conceito e sua gênese do século XIX até hoje; 2) Conceito de cotidiano e mundo vivido, no contexto da pesquisa social e da teoria social. 3) A fenomenologia social delimitada por Husserl e Schütz é ampliada e conturbada nas discussões atuais.

No entanto, por trás de tal universo de debates se esconde uma questão propriamente filosófica: até que ponto não se oculta nos conceitos de mundo, imagem de mundo e mundo vivido, um relativismo conceitual.

Estaria faltando uma distinção e delimitação entre: a) "uma relativa interpretação do mundo" e b) "uma estrutura universal do mundo". Todas as concepções de mundo, interpretações de mundo e imagens de mundo devem ser distinguidas estritamente do mundo em sua estrutura universal; ela mesma não relativa, da qual elas são apenas interpretações.

Esta "função de fundamentação" deve ser radicalmente questionada."

Contra a concepção husserliana de mundo vivido podem ser levantadas duas objeções fundamentais. A primeira é de natureza metódico formal; a segunda, do tipo substancial:

1. Somente na forma de um "núcleo de mundo" construído abstratamente, pode o mundo vivido ser fundamento universal para qualquer afirmação de sentido. A experiência de mundo vivido é determinada como tendo uma experiência fundante e também uma experiência parcial. De um lado, ele é pressuposto em todos os modos de vivência e comportamento e, de outro lado, ele é conquistado, através da separação da experiência concreta, pela abstração.

Waldenfels formula o dilema: "[...] na medida em que o mundo vivido é concreto-histórico, ela não é fundamento universal; e na medida em que é tal [fundamento universal] ele não é concreto-histórico". Como mundo vivido concreto ele não é fundamento e como "núcleo do mundo" não é concreto-histórico".

Veja-se para o que segue o ensaio de Bernhard Waldefels: $A$ abissalidade do sentido. Crítica da idéia husserliana de fundamentação, in E. Ströker (Ed.). 
Neste contexto, Wandenfels exige, com Merleau-Ponty, a revisão geral do esquema de fundação e sua substituição pela relação intercambiante de fundante e fundado.

2. Há, no entanto, uma objeção de caráter substancial. A concepção de Husserl pode servir de fundamento universal, mas como tal é insustentável. Husserl caracteriza a percepção como presentação e présentificação; o percebido possui o modo da presença, da presença corporal - e isto conduziria à aceitação de uma experiência universalmente estruturada fundante. As coisas mesmas estão submetidas a perspectivas espaço-temporais e são superpostas por diversos predicados culturais, mas a percepção pode exercer o papel de um acontecer unificador.

$\mathrm{Se}$, ao contrário, a recepção é entendida como articulação, como um figurador específico e um estruturar, o progresso da experiência pode ser determinado como "reestruturação no sentido de formações de estruturas concorrentes".

Diferenças que surgem, devem então ser entendidas não como diversos fatos da experiência, mas como diferentes modos de organização da experiência.

Torna-se assim visivel uma esfera intermediária de formas de organização alternativas e de linhas de desenvolvimento divergentes, entre simples fatos e estruturas universais.

Deve-se procurar uma unificação, não mais uma síntese universal, mas em processo de transformação e de tradução, nos quais diferenças fundamentais não foram simplesmente supressas. A concepção husserliana de um mundo vivido parece ter que ser, assim, abandonada em favor de uma rede e uma corrente de mundos singulares que se superpõem.

3. Sendo as coisas assim, a relação tradicional entre Ciência e Filosofia também muda.

"Já que a formação de ordens específicas de mundo se subordina, na forma de diversos esquemas de percepção, sistemas de sinais, estruturas de linguagem, formações do eu, socializações, concepções de espaço e tempo - a condições contingentes e contextos históricos e a racionalidade está vinculada indissociavelmente com o fático, também surge na teoria uma esfera intermeđiária onde se cruzam e fecundam os esforços por uma explicação filosófica e as pesquisas especiais" (Waldenfels).

\section{Bibliografia}

BERGMANN, W. Lebenswelt des Alltags oder Alltagswelt? In Köl. Zeitschrift f. Soz. u. Soz-psy. ano 33, 1981.

BLUMENBERG, H. Lebenszeit, Weltzeit, Frkft 1986.

BRAND, G. Lebenswelt ( Die ) - Eine Philosophie der konkreten Erfahrung, Berlin 1971.

CENEN, H. Diesseits von subjektivem Sinn und kollektivem Zwang, München, 1985.

CICOUREL, A. V. Methode und Messung in der Soziologie, Frkft, 1974.

EBERLE, Th. S.Sinnkonstitution in Alltag und Wissenschaft, Bern / Stuttgart, 1984.

FELLMANN, F. Gelebte Philosophie in Deutschland. Denkformen der Lebensweltphänomenologie und der kritischen Theorie, Freiburg/München, 1983. 
GRATHOFF R. - Alltag u. Lebenswelt als Gegenstand der phän. Sozialtheorie, in Materialien zur Soz. des Alltags 1978.

HABERMAS, J. Theorie des Kommunikativen Handels 2 vols. Frkft 1981.

HEIDEGGER, M. Sein und Zeit, Tübingen 1979.

HUSSERL, E. Krisis der europ. Wissenschaften u. die tranz Phän. Husserliana vol. 6.

KIWITZ, P. Lebenswelt und Lebenskunst. Perspektiven einer kritschen Theorie des sozialen Lebens, München 1986.

- Lebenswelt - Zwischen Moderne und Tradition, in Philosophische Rundschau, Ano 33 Fasc 1/2, Tübigen 1986.

LANDGREBE, L. Der Weg der Phänomenologie, München 1963.

LIPPITZ, W. "Lebenswelt" oder die Rehabilitierung vorwissenschaftlicher Erfahrung, Weinheim/Basel 1980.

MATTHIESEN, U. Das Dickicht der Lebenswet und die Th. des Kom. Handels, München 1983.

PRODOEL, H. G. Theorie des Alltags, Berlin 1983.

ROTHACKER, E. Zur Genealogie des menschlichen Bewusstseins,1967.

SCHÜTZ/LUCKMANN, Strukturen der Lebenswelt, vol. 2 Frkft. 1984.

STROKER, E. Lebenswelt und Wissenschaft in der Philosophie E. Husserl, Frkft.1979.

TUGENDHAT, E. Der Wahrheitsbegriff bei Husserl u. Heidegger, Berlin, 1967.

WALDENFELS, B. Im Labyrinth des Alltags, in Ströker E. Lebenswelt und Wissenschaft in der Philosophie E. Husserl, Frkft. 1979.

. In den Netzen der Lebenswelt, Frkft 1985.

WELTER, R. Der Begriff der Lebenswelt. Theorien vortheoretischer Erfahrungswelt, München 1986. 